\title{
Resource depletion: where is an intervention most effective?
}

\author{
Patrick de Laat \\ Universiteit Twente, Enschede, The Netherlands
}

\begin{abstract}
Purpose - Where does one need to intervene in to be most effective? The purpose of this study is to rank areas of the resource system, according to how much of a change can be expected from interventions in an area, in relation to the problem of depleting resources.

Design/methodology/approach - Principles of structured analysis are used to model how society uses resources. From this model, nine intervention areas are defined. These intervention areas are ranked in terms of effectiveness, through the use of the analytic hierarchy process.

Findings - To be most effective, one must prioritize intervention areas as follows: material inputs to the operation phase; process inputs to the operation phase; products' longevity; process inputs to the manufacturing phase; and material inputs to the manufacturing phase.

Practical implications - Most decisions are not made on the basis of rigorous analysis but by using heuristics (rules of thumb). The results of this study are expressed as rules of thumb. They can help decision makers prioritize what is most important, but without imposing new ways of working.

Originality/value - In the construction domain, heuristics that generalize the impact of actions (content), instead of intervention areas (context), currently seem to prevail. The heuristics of this study generalize the impact of intervention areas. Therefore, they provide an extra perspective for many decision makers. This extra perspective can help reduce mistakes that are typically made by oversimplifying matters.
\end{abstract}

Keywords Effectiveness, Efficiency, Sustainability, Heuristics, Intervention areas, Resource depletion

Paper type Research paper

\section{Introduction}

Many authors have pointed out that the current usage of natural resources cannot be maintained forever (Boulding, 1966; Diederen, 2010; McDonough and Braungart, 2002; Meadows et al., 1972; Stahel, 1984). Some claim that society's standards are too high and that this is part of the problem (e.g. Diederen, 2010), whereas others deny that lower standards are necessary to resolve resource depletion (e.g. McDonough and Braungart, 2002). However, all agree that the take, make and dispose approach to achieving those standards is unsustainable. A substantial share of resource usage, and therefore the problem, is related to the construction sector (see Krausmann et al., 2009).

According to Rittel and Webber (1973, p. 159), with such problems, known as "wicked problems", it is "[...] less apparent where and how we should intervene even if we do happen to know what aims we seek." Practitioners often use heuristics, i.e. rules of thumb, to make such decisions (see Persson and Ryals, 2014) because the available time to both search for information and make tough decisions is limited in real-world decisions.

A distinction can be made between two types of heuristics (rules of thumb): rules that prioritize certain actions; and rules that prioritize certain intervention areas. An example of the first type is the triad approach. It prescribes the following sequence of actions,

(C) Patrick de Laat. Published by Emerald Publishing Limited. This article is published under the Creative Commons Attribution (CC BY 4.0) licence. Anyone may reproduce, distribute, translate and create derivative works of this article (for both commercial \& non-commercial purposes), subject to full attribution to the original publication and authors. The full terms of this licence may be seen at http:// creativecommons.org/licences/by/4.0/legalcode

This work was partially funded by the European Union's Horizon 2020 research and innovation program under Grant Agreement No. 642384. The author thanks M. Mohammadi, M.M.T. Dominicus and J.J.N. Lichtenberg for their guidance during the first half of this research project.

Received 10 February 2018 Revised 26 September 2018 Accepted 22 January 2019

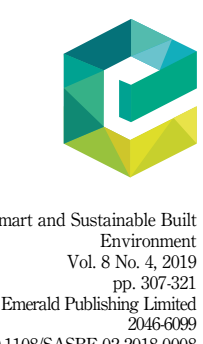

DOI 10.1108/SASBE-02-2018-0008 
SASBE 8,4 ranging from most to least effective: prevention of unnecessary use; substitutional use; and prudent conduct (see Entrop and Brouwers, 2010). An example of the second type is to prioritize energy efficiency during a building's daily operation over energy efficiency during its construction. In the first type of heuristics, one generalizes the impact of content, irrespective of its context. In the second type, one generalizes the role of context, irrespective of its content.

Rules of thumb can be very useful. However, many mistakes are made when practitioners rely on heuristics that they have developed informally themselves over time and based on their own experiences (see Tversky and Kahneman, 1974). Therefore, there is a value in developing such heuristics in a more systematic manner. This study focuses on heuristics of the second type, i.e. rules that prioritize certain intervention areas. Of the two types, this type is arguably the least established within the field of construction.

\section{Method}

\subsection{Introduction}

This study's aim is to rank areas of the resource system, according to how much of a change can be expected from interventions in an area, in relation to the problem of depleting resources. In other words, where does one need to intervene in to be most effective? First, the areas are defined. After that, they are compared and ranked.

\subsection{Step 1: define the areas}

The resource system can be viewed in two ways: as a process, i.e. a sequence of steps (e.g. Stahel, 1984); or as a hierarchy, i.e. a cumulation of levels (e.g. Meadows, 1999). In this study, the process perspective has been adopted to define the intervention areas. To first define levels and afterwards rank them is only possible in this perspective. In the hierarchy perspective, the ranking of levels is the relation between levels.

The following principles of structured analysis (Ross, 1977) are used to create a process perspective of the resource system: each model must have precisely one "viewpoint" and one "purpose"; nothing which fits the purpose and viewpoint may be excluded; each model must be composed of "things" and "happenings"; and each model must be composed of neither too few nor too many pieces. Boulding (1966) noted that a perspective with too much emphasize on "throughput" may be part of the problem. Therefore, stocks have been added to the list of building blocks (things and happenings). The intervention areas will become clear from the resulting model.

\subsection{Step 2: compare and rank the areas}

According to Saaty (1990, p. 12), "the most effective way to concentrate judgement is to take a pair of elements and compare them on a single property without concern for other properties." When this has been done for all elements and all properties, the results are added together. This is termed the analytic hierarchy process. The effectiveness of intervening in an area is determined by the following two properties: how much there is to be gained in an area; and how much an intervention in an area is expected to snowball, i.e. to cause a snowball effect.

The first property is composed of both: the initial amount and its previous exploitation, i.e. how much of that amount has already been exploited. Hayek (1967, pp. 96-105) used the term "human action" to describe something that happened without purposeful human design but not without human influence. The initial amount is a result of human action, whereas the previous exploitation is a result of purposeful human design.

This distinction is useful because an area's previous exploitation indicates how effective future exploitations of that area will be. In economics, there is a rule of thumb named 
"the law of diminishing returns" (Oxford Dictionary of Economics, 2012). It states that a continuing application of effort toward a particular goal will decline in effectiveness after a certain level of result has been achieved (cf. von Bertalanffy, 1968, pp. 60-63). In other words, when an area has already been substantially exploited, future interventions will be increasingly less effective.

The second property also comprises two parts: the connectedness between areas and the range of potential interventions. First, when an area is closely connected to other areas, a change in that area will ripple through the areas directly next to it. This ripple effect will not happen in an isolated area. Thus, more of a snowball effect is expected in more connected areas. Second, only certain interventions are possible within each area. Some interventions cause more of a snowball effect than others. Thus, when such interventions are not possible within an area, less of a snowball effect can be caused there. However, more of an effect is expected from interventions in areas where the less effective interventions are not possible.

Table I shows how the intervention areas will be compared. First, the areas are scored (between 1 and 5) on each sub-property. These scores are all relative. They are based on answers for the following type of question: why is area $(\mathrm{x})$ better/worse in property $(\mathrm{y})$ than others? Each score is then multiplied by a weighting factor (1/3rd or $1 / 6$ th) because two of the properties are more important than the others. The final score is calculated by adding the weighted scores together.

\section{Results}

\subsection{A process perspective}

3.1.1 Introduction. Figure 1 shows the process of using resources. A gray box represents a stock and a white box represents an activity. The symbols (-) and (+) show when things are subtracted from or added to a stock, respectively, whereas the symbols $(--)$ and $(++)$ show when something is consumed or generated, respectively. Furthermore, the symbols (») and («) show when products' lifespans are unfavorably or favorably affected, respectively.

3.1.2 Viewpoint and purpose. The "viewpoint" is the topic of a structured analysis (Ross, 1977, p. 18), in this case: resource usage. The "purpose" determines the importance of things and happenings in the systemization (Ross, 1977, p. 18). It determines what is and what is not to be included from the viewpoint. The purpose of this model is to optimize resource effectiveness in the interests of the collective, i.e. humankind.

Owning or having access to certain amounts of particular products is a universal preference. Through the use of such products, people attain something intangible that is termed material well-being. Material well-being is seen as a condition of the psyche (see Boulding, 1966, pp. 8-10) that lessens overtime and is supplemented through the use of products. In other words, material well-being is a stock that regularly needs to be replenished. The optimum level of material well-being that should be strived for - and its

\begin{tabular}{|c|c|c|c|c|c|}
\hline $\begin{array}{c}\text { Intervention } \\
\text { areas }\end{array}$ & $\begin{array}{c}\text { Scores } \\
\text { on (1a) } \\
\text { Initial } \\
\text { amount }\end{array}$ & $\begin{array}{c}\text { Scores } \\
\text { on }(1 b) \\
\text { Previous } \\
\text { exploitation }\end{array}$ & $\begin{array}{c}\text { Scores } \\
\text { on }(2 \mathrm{a}) \\
\text { Connectedness } \\
\text { between areas }\end{array}$ & $\begin{array}{c}\text { Scores } \\
\text { on }(2 b) \\
\text { Range of } p \text {. } \\
\text { interventions }\end{array}$ & $\begin{array}{r}\text { Final } \\
\text { scores }\end{array}$ \\
\hline Area 1 & Score $\cdot(1 / 3$ & Score $\cdot(1 / 6)$ & + Score $\cdot(1 / 3)+$ & Score $\cdot(1 / 6)=$ & ... \\
\hline Area 2 & Score $\cdot(1 / 3$ & Score $\cdot(1 / 6)$ & Score $\cdot(1 / 3)+$ & Score $\cdot(1 / 6)=$ & $\ldots$ \\
\hline Area 3 & Score $\cdot(1 / 3$ & Score $\cdot(1 / 6)$ & Score $\cdot(1 / 3)$ & Score $\cdot(1 / 6)=$ & $\ldots$ \\
\hline
\end{tabular}

Table I. How the intervention areas will be compared 
SASBE

8,4

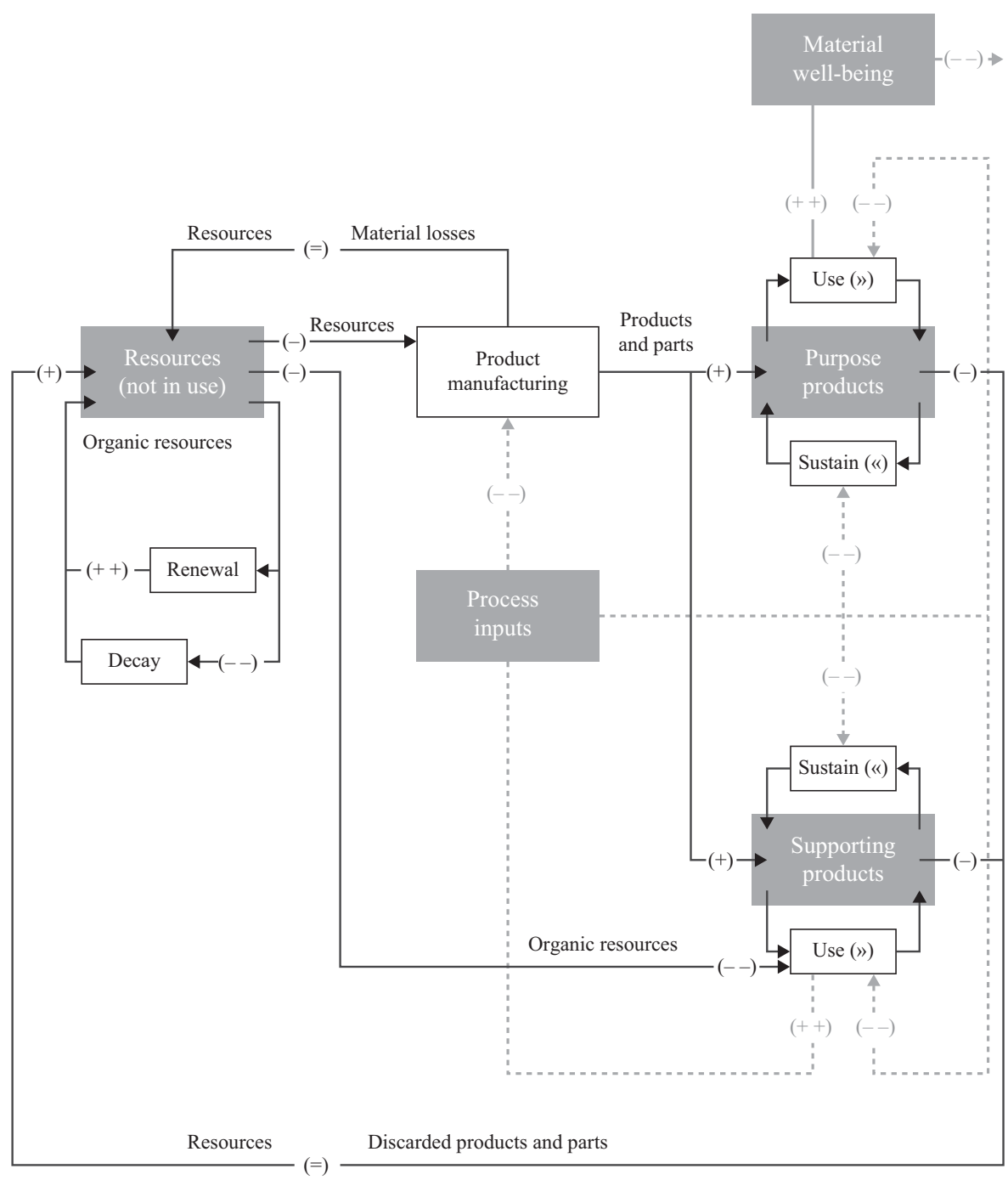

\section{0}

Figure 1.

The process of using resources

Notes: A gray box represents a stock and a white box represents an activity. The symbols (-) and $(+)$ show when things are subtracted from or added to a stock, respectively, while the symbols $(--)$ and $(++)$ show when something is consumed or generated, respectively. Furthermore, the symbols (») and («) show when products' lifespans are unfavorably or favorably affected, respectively

distribution amongst society - is beyond the scope of this study. However, maximizing the level of material well-being that can be sustained provides the most suitable boundary conditions for addressing resource allocation.

3.1.3 Phases. A distinction can be made between two phases: the manufacturing phase and the operation phase. Eekhout (1997, pp. 27-33) described the process of manufacturing building products in six steps: raw materials are purified to mono-materials; mono-materials 
are mixed to form composites; composites are shaped to materials of commerce; materials of commerce are adapted to elements; elements are assembled into components; and components are assembled into products. This sequence of steps is universally applicable, though not all manufacturing processes go through all the steps. Each process always starts with a resource. Thus, before any of these six steps can happen, resources need to be extracted (step 0). Also, all products are made for a purpose. After all the other steps have been completed, the product is handed over (step 7). In the construction sector, this generally means that the product is placed or installed at a specific location.

When a product is handed over, this conventionally means that its ownership is also handed over. The operation phase is associated with the concept of ownership. The operation phase begins when the product is handed over to a consumer. It ends when this ownership ends. Ownership can end in two ways: a party willingly takes over the product; or it is disposed off. In the first situation, the product's removal is the first step of the manufacturing phase, i.e. the extraction of a resource. In the second situation, the product's disposal is the final step of the operation phase. Afterwards, if the product is salvaged from the place it was dumped at, this salvaging action is the first step of a new manufacturing phase.

Furthermore, products' longevity is closely associated with the phases. Though it cannot be referred to as a phase itself, products' longevity does determine the relative importance of the manufacturing phase versus the operation phase. With longer lifespans, the operation phases become longer. Therefore, products do not need to be remanufactured as often.

3.1.4 Material inputs. Materials can be classified as either organic or inorganic (Czichos, 2006). Organic materials can then be classified as materials that quickly renew (grow back) or materials that require a long time to renew. This distinction is useful because even crude oil is organic in origin (see Oxford Dictionary of Chemical Engineering, 2014), despite the fact that almost no oil "grows back" in a generation's lifetime because its renewal rate is so low.

Material inputs are presented (in Figure 1) as something which is only redistributed and reconfigured. There are two exceptions: the renewal and decay of organic resources; and the incineration of organic resources to generate energy. Other than that, there is no way for resources to enter or leave the system. This may seem somewhat counter-intuitive in relation to the concept of waste. However, waste is not a physical loss of resources but a loss in value. As people extract materials from their natural settings rather than from disposed and valueless products, it must be easier and cheaper to exploit virgin resources. In other words, due to the initial manufacturing process, materials have become less suitable for future manufacturing processes.

For energy, the concept of exergy, which describes the usefulness of energy states (Rant, 1956), was introduced to describe such a loss of usefulness. A similar concept can be used to describe the usefulness of material states, as matter and energy are alike in the fact that it is more troublesome to concentrate diffused particles than it is to diffuse concentrated ones (cf. Diederen, 2010, p. 8). In Figure 1, both material losses in manufacturing and discarded products and parts in operation are categorized as resources. They both only differ from virgin resources in terms of material states.

3.1.5 Process inputs. All products do not contribute in the same way to material well-being. A distinction is made between products that contribute directly and those that contribute indirectly to material well-being. For example, a pair of trousers fulfils a clear purpose; a person benefits directly from wearing it. Such a product is referred to as a purpose product. A washing machine, on the other hand, makes it easier to maintain products such as a pair of trousers. People do not benefit from a washing machine in and of itself. However, it improves the ease of use of other products greatly. Such a product is referred to as a supporting product. This distinction is useful because products that have a more direct link to material well-being are harder to change without affecting their contribution to material well-being. 
SASBE 8,4

Table II.

The nine intervention areas
In Figure 1, the relation between purpose products and supporting products is shown as follows: supporting products produce process inputs; and the consumption of such inputs represents the use of such products. This is similar to how a layperson, i.e. a non-physicist, describes energy: a source that is generated and consumed. For supporting products, this description makes sense from the perspective of products' technical lifespan (see Gijsbers, 2011, pp. 21-23). All products undergo wear and tear that will eventually break them down.

From this perspective, a screwdriver does not differ from a solar panel. Both are made to provide a certain supporting service. For the solar panel, this service is generating energy. For the screwdriver, this service is tightening and loosening screws. A solar panel is limited in the amount of energy it can generate in its lifetime because all products only remain functional for a limited time. Similarly, a screwdriver is limited in the amount of times it can be used. A process input represents a supporting product's functional contribution. This can, thus, be an amount of energy but also the application of a product.

3.1.6 Number and types of inputs. In Figure 1, the inputs to an activity (e.g. product manufacturing) are described in two ways: by their number or amount; or by their types (cf. von Bertalanffy, 1968, p. 54). For example, an input can represent many resources or a few resources, and an input can represent organic resources or inorganic resources. When the efficiency of a process changes, it requires a changed amount of inputs. A focus on the number of inputs is a focus on efficiency. However, a focus on the types of inputs is different. When a number of inputs, of a certain type, is replaced by a number of inputs, of another type, inputs are redistributed. With a focus on redistribution, the purpose for what a type of resource is best employed for is reconsidered.

3.1.7 Intervention areas. From the model, nine intervention areas are defined. These areas are listed in Table II. An area is defined by three focusses. Each area focusses on either the manufacturing phase or the operation phase. Within this main scope, each area focusses on material inputs or process inputs. Within this sub-scope, each area focusses on the number of inputs or the types of inputs. However, the ninth area is an exception. It does not focus on one of the phases, but instead it focusses on the longevity of products. Products' longevity determines the relative importance of the manufacturing phase vs the operation phase. With longer lifespans, the operation phases become longer. Therefore, products do not need to be remanufactured as often. The manufacturing process consumes process inputs (see Figure 1). So, when products do not need to be remanufactured as often, fewer process inputs are required for manufacturing. This is the numerical effect of an intervention in products' longevity.

Nonetheless, the effects of such interventions are mostly visible during the operation phase. Buildings last longer when it is easy to modify them (adaptable buildings) and when it is easy to use them differently (flexible buildings). Both these activities are related to the operation phase. When a building is adaptable, it is easily modified. Therefore, when a part of such a building needs to be updated, it is easier to make space for the update. This implies

\begin{tabular}{llr}
\hline No. & Description & Code \\
\hline 1 & (a) number of (a) material inputs (a) to manufacturing & a.a.a \\
2 & (b) types of (a) material inputs (a) to manufacturing & b.a.a \\
3 & (a) number of (b) process inputs (a) to manufacturing & a.b.a \\
4 & (b) types of (b) process inputs (a) to manufacturing & b.b.a \\
5 & (a) number of (a) material inputs (b) to operations & a.a.b \\
6 & (b) types of (a) material inputs (b) to operations & b.a.b \\
7 & (a) number of (b) process inputs (b) to operations & a.b.b \\
8 & (b) types of (b) process inputs (b) to operations & b.b.b \\
9 & (c) products' longevity & c
\end{tabular}


a numerical effect on the process inputs to the operation phase. However, in a non-adaptable building, such an update will often be too costly. Instead, updates are postponed until the entire building is replaced, which would happen a lot sooner without updates. So, despite the fact that an intervention in products' longevity mostly changes how the operation phase works, it mostly has a numerical effect on the manufacturing phase. Neither of the two phases completely cover the effects of an intervention in products' longevity. Therefore, products' longevity is set apart as a separate area.

\subsection{Ranking}

3.2.1 Introduction. In this section, all areas are ranked, i.e. put in a sequence from best to worst. A separate ranking is made for each of the following sub-properties: initial amount; previous exploitation; connectedness between areas; and range of potential interventions. Each area is given a score of between 1 and 5 based on its position in a ranking. Priority is given to providing a complete picture. So, some reasons behind a ranking will be better than others. Markings are used to clarify the author's thoughts about the validity of an area's rank. Each time a rank is assigned, it is marked with either (**) two asterisks, $(*)$ one asterisk or $(-)$ no asterisks. The number of asterisks symbolizes the author's confidence in the ranking, in which more asterisks signifies more confidence (this marking system is adopted from Alexander et al., 1977, pp. xiv-xv).

Finally, one comparison of areas is done differently, namely: number of inputs vs types of inputs. This comparison will be addressed separately further on. For now, that means that the following five areas are compared first: material inputs to manufacturing (a.a); process inputs to manufacturing (b.a); material inputs to operations (a.b); process inputs to operations (b.b); and products' longevity (c).

3.2.2 Initial amount. Table III shows how the five areas are ranked according to how much there initially was to be gained in an area. There are three reasons behind this ranking. Reason No. 1: a shortage of materials is the same problem as a shortage of process inputs. A distinction can be made between "resource reserves" and the "resource base" (Ashby, 2012, pp. 32-33). The resource base represents all resources that exist on this planet. The resource reserves represent a share of the resource base. It includes all resources that can be accessed using today's technology for a reasonable price. Many authors (e.g. Allwood et al., 2011; Boulding, 1966; Diederen, 2010; Meadows et al., 1972) seem to believe that depleting resources does not mean that the base is running out of resources, but that the reserves are depleting.

When the reserves of a specific resource are running out, there are two options: not to use the material anymore because it has become too costly to extract; or reserve a greater share of all process inputs for its extraction because the resource cannot be missed. A lack of a specific material can, thus, be compensated for by allocating more process inputs. On the other hand, insufficient process inputs makes the extraction of materials more difficult. A shortage of materials and a shortage of process inputs cannot be isolated from one another; they represent the same problem.

\begin{tabular}{llcc}
\hline Rank & Area & Score & Validity \\
\hline 1 & Material inputs to operations (a.b) & 5 & $* *$ \\
& Process inputs to operations (b.b) & 5 & $* *$ \\
& Products' longevity (c) & 3 & - \\
& Material inputs to manufacturing (a.a) & 3 & $*$
\end{tabular}

Notes: A score of 5, 3 or 1 means that an area scores best, neutral or worst, respectively, on this sub-property. "-" means author is least confident in the validity of the ranking; *** means author is averagely and most confident in the validity of the ranking

Resource depletion 
SASBE 8,4

314

Reason No. 2: more can be gained in operations than in manufacturing. Of the two, the operation phase is the most significant phase because buildings and building products last a long time. For example, the exterior of a building changes "every 20 years or so" and its installations "wear out or obsolesce every 7 to 15 years" (Brand, 1994, p. 13). Also, a house lasts on average about 30 years in Japan, 55 years in the USA and 77 years in the UK (Eguchi et al., 2011, p. 74, Figure 1).

The time that a house is used can be more than 50 times as long as the time it takes to construct it (e.g. 9 months of construction and 50 years of use). During that time, a building requires a lot of energy, for example for heating and lighting; "it has been confirmed [by several studies] that operation energy is by far the most important contributor to life cycle impacts of conventional buildings" (Blengini and Di Carlo, 2010, p. 869).

Furthermore, not all materials pass through the manufacturing phase before they go into the operation phase: some are immediately combusted to generate energy. These processes are a main cause of too much greenhouse gases being released into the atmosphere and that, as a result, the climate is changing (United Nations, 1992). It can be assumed that lots of materials are involved in this process because the topic is so popular in environmental policy. The operation phase involves more materials, than the manufacturing phase, in this regard. However, a similar claim can also be made for manufacturing: not all materials that are processed in the manufacturing phase end up in the final products. For example, Hicks et al. (2004, p. 170) studied a manufacturing process in which (about) 23 percent of incoming materials were wasted by the end of the process. This is referred to as yield loss (Allwood et al., 2011, p. 365).

Reason No. 3: products' longevity and the manufacturing phase are also significant intervention areas. Seeing how the average lifespan of houses varies across different cultures, each with their own construction methods, gives some idea about how much longevity can be gained by a good design, a suitable financial model and a suitable construction process. However, research mostly highlights the importance of the operation phase. Little information points toward the potential of the manufacturing phase or products' longevity. Therefore, these areas are given a neutral score (3).

3.2.3 Previous exploitation. Table IV shows how the five areas are ranked according to how little of an area has already been exploited. There are three reasons behind this ranking. Reason No. 1: operation energy has been a very popular intervention area. For example, the European Parliament's (2010) energy directive mandates that future buildings have to be built as "nearly zero-energy buildings." It is no wonder that "[...] especially for new and low energy buildings, the relative role and the importance of life cycle phases are changing" (Blengini and Di Carlo, 2010, p. 869). However, only 0.25 percent of old houses are replaced annually in the Netherlands (Thomsen and van der Flier, 2009, p. 653). Thus, it will take quite some time before all houses are nearly zero-energy buildings.

Reason No. 2: the manufacturing phase has not received the same amount of attention as operation energy. The manufacturing phase has received some attention. For example, yield

Table IV.

The ranking of intervention areas in terms of the previous exploitation

\begin{tabular}{llcc}
\hline Rank & Area & Score & Validity \\
\hline 1 & Products' longevity (c) & 4 & $*$ \\
2 & Material inputs to manufacturing (a.a) & 3 & - \\
& Process inputs to manufacturing (b.a) & 3 & $*$ \\
3 & Material inputs to operations (a.b) & 3 & $*$
\end{tabular}

Notes: A score of 5, 3 or 1 means that an area scores best, neutral or worst, respectively, on this sub-property. "-_ means author is least confident in the validity of the ranking; *** means author is averagely and most confident in the validity of the ranking 
losses in Sweden have been halved in eight years' time (Shahbazi et al., 2016). This attention just has not been at the same level as the attention to reducing operation energy.

Reason No. 3: of the five areas, products' longevity has received the least attention. There are even clear signs that the longevity of some products is decreasing (e.g. the longevity of personal computers (see Babbitt et al., 2009)). This may be because the threshold is higher for intervening in longevity; the interventions are not straightforward.

3.2.4 Connectedness between areas. Table V shows how the five areas are ranked according to how connected an area is to other areas. Figure 2 shows how an intervention in one area affects the others. In the matrix in Figure 2, the following four areas are represented by both a row and a column: material inputs to manufacturing; process inputs to manufacturing; material inputs to operations; and process inputs to operations. Thus, the matrix comprises four rows and four columns.

A number 1 is placed in all cells across the diagonal. The number 1, within a row, represents the focus area, i.e. the area that people try to change through an intervention. Next, horizontal arrows start from a number 1 cell and end up in cells, within the same row, that are marked with the number 2. The arrows represent a ripple effect. An intervention's effect on a number 1 cell ripples through the number 2 cells within the same row. After that, the effect on a number 2 cell ripples further (although, the effect becomes increasingly less). How this effect ripples further is made clear by the vertical arrows. For every number 2 cell, a vertical arrow points towards the row that describes its further progress.

\begin{tabular}{llcc}
\hline Rank & Area & Score & Validity \\
\hline 1 & Material inputs to operations (a.b) & 5 & $* *$ \\
2 & Products' longevity (c) & 3 & - \\
& Process inputs to operations (b.b) & 3 & $*$ \\
& Process inputs to manufacturing (b.a) & 3 & $*$
\end{tabular}

Notes: A score of 5, 3 or 1 means that an area scores best, neutral or worst, respectively, on this sub-property. "-" means author is least confident in the validity of the ranking; *** means author is averagely and most confident in the validity of the ranking

Table V. The ranking of intervention areas in terms of the connectedness between areas

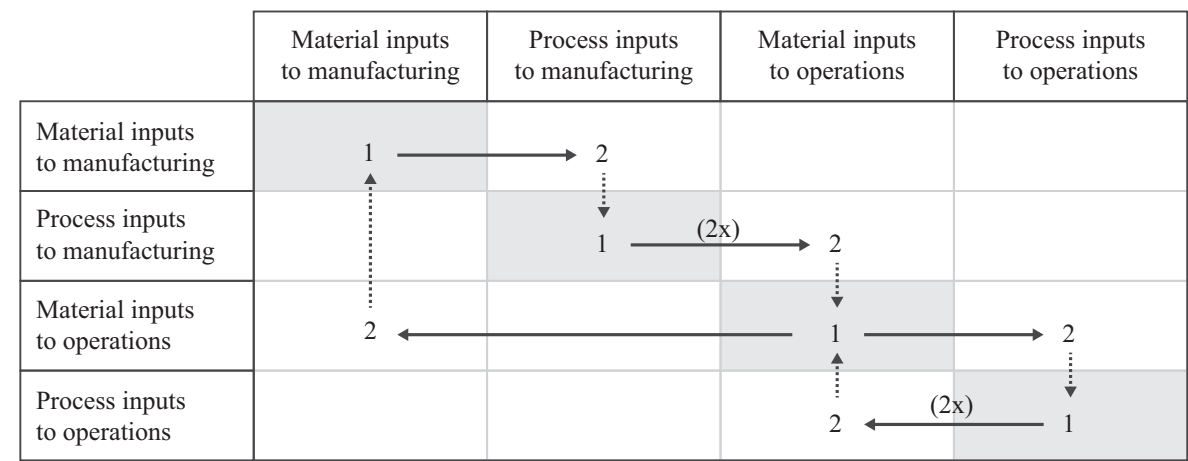

Notes: A number 1 cell represents the focus area. The horizontal arrows represent a ripple effect. An intervention's effect on a number 1 cell ripples through the number 2 cells within the same row. How this effect ripples further is made clear by the vertical arrows. For every number 2 cell, a vertical arrow points toward the row that describes its further progress
Figure 2.

How an intervention in one area affects the others 
SASBE 8,4

\section{6}

Table VI.

The ranking of intervention areas in terms of the range of potential interventions
The first row of the matrix describes the following: when less material goes into the manufacturing process, fewer process inputs are required (assuming a constant requirement per processed quantity of material). The third row describes something similar: when fewer products are used, fewer process inputs are required. For example, each product requires some maintenance. Thus, when people have more products, they have more things to maintain. However, the third row also describes a situation in which fewer products are used, and therefore, fewer products need to be made. This affects the material inputs to manufacturing. However, this does not hold true for the other way around; less material can be used in manufacturing without making fewer products (e.g. by making lighter products).

The second and fourth rows of the matrix describe the following: when fewer process inputs are required, fewer supporting products are needed to generate such inputs, and fewer inputs will be combusted for generating energy, i.e. two times a reduction of material inputs to the operation phase. An intervention in the inputs that are combusted for generating energy is the only type of intervention that does not have a further effect on any of the other areas.

In summation: an intervention in the material inputs to operations indirectly affects two other areas; an intervention in the process inputs affects one other area in two different ways, and only one of those ways has a further effect on another area; and an intervention in the material inputs to manufacturing only affects one other area. Products' longevity is scored the same as the process inputs to the manufacturing phase because an intervention in longevity only has a numerical effect on this area (see Section 3.1.7).

3.2.5 Range of potential interventions. Table VI shows how the five areas are ranked in terms of their range of potential interventions. The reasons behind this ranking are as follows: all potential interventions in products' longevity cause a considerable snowball effect; none of the potential interventions in manufacturing cause much of a snowball effect; and some of the potential interventions in operations cause a considerable snowball effect, and some do not.

According to Meadows (1999), one of the greatest snowball effects is achieved by changing the "rules" of a system. On the other hand, changing the "parameters" of a system does not cause much of a snowball effect. The parameters of a system include everything that can be described by a number. For example, the number of elements is a parameter, but also the strength of a relation between two elements. The rules of a system describe where the relations between elements are placed and how they work (cf. Meadows, 1999, pp. 5-7; von Bertalanffy, 1968, pp. 54-55). Table VII lists 14 interventions in resource usage that have been mentioned by other authors. For each of these interventions, Table VII shows the following: the target area; and whether the intervention affects the system's parameters or the system's rules.

Light-weighting, i.e. making products that contain less material, is an example of an intervention in the system's parameters. Such an intervention changes the product, but it

\begin{tabular}{llcc}
\hline Rank & Area & Score & Validity \\
\hline 1 & Products' longevity (c) & 4 & $*$ \\
2 & Material inputs to operations (a.b) & 3 & $*$ \\
& Process inputs to operations (b.b) & 3 & $* *$ \\
3 & Process inputs to manufacturing (b.a) & 2 & -
\end{tabular}

Notes: A score of 5, 3 or 1 means that an area scores best, neutral or worst, respectively, on this sub-property. "-" means author is least confident in the validity of the ranking; *** means author is averagely and most confident in the validity of the ranking 


\begin{tabular}{|c|c|c|c|c|}
\hline Source & Intervention & Target area & Type & $\begin{array}{l}\text { esource } \\
\text { epletion }\end{array}$ \\
\hline Allwood et al. (2011) & Increased recycling rates & p. inputs to manufacturing & Parameters & \\
\hline Allwood et al. (2011) & Yield improvement & m. inputs to manufacturing & Parameters & \\
\hline Allwood et al. (2011) & More intense use & m. inputs to operations & Rules & \\
\hline Allwood et al. (2011) & Remanufacturing & p. inputs to manufacturing & Parameters/rules & \\
\hline Allwood et al. (2011) & Component re-use & p. inputs to manufacturing & Parameters/rules & \\
\hline Allwood et al. (2011) & Light-weighting & m. inputs to manufacturing & Parameters & 317 \\
\hline Stahel (2010) & Performance based leasing & p. inputs to operations & Rules & \\
\hline Bocken et al. (2016) & Emotional durability & Products' longevity & Rules & \\
\hline Bocken et al. (2016) & Physical durability & Products' longevity & Parameters/rules & \\
\hline Bocken et al. (2016) & Reliability & Products' longevity & Parameters/rules & \\
\hline Bocken et al. (2016) & Ease of maintenance and repair & Products' longevity & Rules & \\
\hline Bocken et al. (2016) & Upgradability and adaptability & Products' longevity & Rules & \\
\hline Bocken et al. (2016) & Standardization and compatibility & Products' longevity & Rules & \\
\hline Bocken et al. (2016) & Dis- and reassembly & Products' longevity & Rules & $\begin{array}{l}\text { ence } \\
\text { Irce }\end{array}$ \\
\hline \multicolumn{4}{|c|}{$\begin{array}{l}\text { Note: They are categorized in both target area and type, i.e. whether the intervention affects the system's } \\
\text { parameters or the system's rules }\end{array}$} & $\begin{array}{l}\text { mentioned by } \\
\text { other authors }\end{array}$ \\
\hline
\end{tabular}

does not change how the product is handled, and therefore, it does not cause much of a snowball effect. Selling things on a performance based lease (see Stahel, 2010) is an example of an intervention in the system's rules. Normally, a person buys a product and becomes its owner. Then, if the product is not working as it should be, or if it is not as efficient as it should be, a person can complain and, the next time, he or she can buy a different product. However, when the manufacturer remains responsible for the performance of the product, the situation will be different. For example, when the product wastes energy, the owner has to pay for that. When the manufacturer is the owner, they will be stimulated to improve on such aspects of their product. This changes how the product is handled, and therefore, it causes a considerable snowball effect.

In Table VII, four interventions are categorized as the type parameters/rules. This means that these interventions are harder to put in one of the two categories. For example, there are two ways to interpret remanufacturing and component re-use: as new relations, i.e. material flows that previously did not exist; or as a strengthened relations, i.e. more product and parts are re-used and remanufactured than they used to be. For this ranking, these four borderline cases are put in the same category as other interventions associated with the same area. Thus, remanufacturing and component re-use affect a system's parameters, whereas physical durability and reliability affect a system's rules.

3.2.6 Number of inputs vs types of inputs. As mentioned previously, one comparison is done in a different way than the others: number of inputs vs types of inputs. In previous comparisons, one intervention area was compared to another to see which one leads to the biggest change. However, this comparison focusses on how a change affects the core problem, regardless of how big a change it is. The "law of the minimum" states that the growth of an organismic system is always limited by the amount of the essential element most closely approaching the critical necessary minimum (Danger et al., 2008; Gorban et al., 2011). In other words, a resource's impact on the system is determined by two things: how limited the resource is and how essential the resource is.

When the efficiency of a process changes, it requires a changed amount of inputs. A focus on the number of inputs is a focus on efficiency. However, a focus on the types of inputs is different. When a number of inputs, of a certain type, is replaced by a number of inputs, of another type, inputs are redistributed. With a focus on redistribution, the purpose for what a type of resource is best employed for is reconsidered. 
SASBE 8,4

A focus on efficiency is straightforward: to improve efficiency, inputs must be lowered, whereas the output stays the same. As a result, fewer resources are needed, and this will help to avoid the depletion of those particular resources. A focus on redistribution is complicated. To improve distribution, the following information is required: how limited resource A is; how essential resource A is; how limited resource B is; and how essential resource $B$ is. Only then can one determine which of the two is scarcer. Next, to improve the distribution of resources, more of the less critical resource is used instead of the scarcer resource. A person can only focus on redistribution when he or she has information about how limited and essential resources are. Otherwise, he or she cannot know if a change would make the situation better or worse. For a focus on efficiency, this information can be helpful, but it is not necessary to make an improvement. Therefore, it is more likely that a more critical resource will be involved in a focus on redistribution.

Furthermore, the strategy of optimizing distribution works toward the end goal of no scarcity and no abundance. All resources will be equally scarce or abundant. All steps move towards this goal. The strategy of optimizing efficiency works towards the end goal of using nothing of a particular resource at all. In the strategy of optimizing distribution, the most critical resource will be dealt with sooner or later. However, in the strategy of optimizing efficiency, this is not necessarily the case. A person could repeatedly try to make one resource more efficient and, therefore, never proceed to a next one.

3.2.7 Final ranking. Table VIII shows the final ranking. Each area has been given a score for each determining sub-property. The final score is calculated by multiplying each score by a weighting factor and by then adding the weighted scores together. The highest rank is given to the highest score. An intervention in the types of inputs is preferred over an intervention in the number of inputs (see Section 3.2.6). However, the distinction in number of inputs and types of inputs has been dealt with in a different way than the other distinctions: a distinction in the manufacturing phase and the operation phase; and a distinction in material inputs and process inputs. Therefore, the distinction in number of inputs and types of inputs has no effect on the general ranking. The preference for an intervention in the types of inputs has been made clear by the addition of the letter $a$ to a rank, instead of the letter $b$.

\section{Discussion and conclusion}

\subsection{Discussion}

In the Introduction, two types of heuristics were mentioned: rules that prioritize certain actions; and rules that prioritize certain intervention areas. The first type is easier to use; a person just does the action that is prescribed. For the second type, there are two options. Option 1: a person picks the intervention area that is prescribed and comes up with an action that focusses on that particular area. Option 2: for each action that a person is considering, he or she thinks of the intervention area that it focusses on. That person then picks the action that focusses on the most important intervention area.

To use heuristics of the second type, a good understanding is required of how actions affect the system. In this case, a good understanding is required of Figure 1. That makes it harder for decision makers to use such rules of thumb. However, when they do invest the time that is needed to learn how to use such heuristics, they will be more aware of what they are using. As a result, decision makers will make fewer mistakes; they will not use generalizations when they are not applicable. By following rules of thumb that prescribe actions, on the other hand, it is easy to oversimplify matter.

In this study, priority was given to providing a complete picture. Therefore, further improvements are necessary, especially in the individual sub-scores. The asterisks show 


\begin{tabular}{|c|c|c|c|c|c|c|c|}
\hline Intervention areas & $\begin{array}{c}\text { Scores } \\
\text { on (1a) } \\
\text { initial } \\
\text { amount }\end{array}$ & $\begin{array}{c}\text { Scores } \\
\text { on (1b) } \\
\text { previous } \\
\text { exploitation }\end{array}$ & $\begin{array}{c}\text { Scores } \\
\text { on }(2 \mathrm{a}) \\
\text { connectedness } \\
\text { between areas }\end{array}$ & $\begin{array}{c}\text { Scores } \\
\text { on }(2 \mathrm{~b}) \\
\text { range of } \mathrm{p} \text {. } \\
\text { interventions }\end{array}$ & $\begin{array}{c}\text { Final } \\
\text { scores }\end{array}$ & $\begin{array}{l}\text { Number } \\
(-) \text { or } \\
\text { types }(+)\end{array}$ & $\begin{array}{l}\text { Final } \\
\text { rank }\end{array}$ \\
\hline $\begin{array}{l}\text { (b) Types of } \\
\text { (a) material inputs } \\
\text { (b) to operations }\end{array}$ & $5 \cdot(1 / 3)$ & $3 \cdot(1 / 6)$ & $5 \cdot(1 / 3)$ & $3 \cdot(1 / 6)$ & $41 / 3$ & + & $1 \mathrm{a}$ \\
\hline $\begin{array}{l}\text { (a) number of } \\
\text { (a) material inputs } \\
\text { (b) to operations }\end{array}$ & $5 \cdot(1 / 3)$ & $3 \cdot(1 / 6)$ & $5 \cdot(1 / 3)$ & $3 \cdot(1 / 6)$ & $41 / 3$ & - & $1 b$ \\
\hline $\begin{array}{l}\text { (b) types of } \\
\text { (b) process inputs } \\
\text { (b) to operations }\end{array}$ & $5 \cdot(1 / 3)$ & $2 \cdot(1 / 6)$ & $3 \cdot(1 / 3)$ & $3 \cdot(1 / 6)$ & $31 / 2$ & + & $2 \mathrm{a}$ \\
\hline $\begin{array}{l}\text { (a) number of } \\
\text { (b) process inputs } \\
\text { (b) to operations }\end{array}$ & $5 \cdot(1 / 3)$ & $2 \cdot(1 / 6)$ & $3 \cdot(1 / 3)$ & $3 \cdot(1 / 6)$ & $31 / 2$ & - & $2 b$ \\
\hline $\begin{array}{l}\text { (c) products' } \\
\text { longevity }\end{array}$ & $3 \cdot(1 / 3)$ & $4 \cdot(1 / 6)$ & $3 \cdot(1 / 3)$ & $4 \cdot(1 / 6)$ & $31 / 3$ & - & 3 \\
\hline $\begin{array}{l}\text { (b) types of } \\
\text { (b) process inputs } \\
\text { (a) to manufacturing }\end{array}$ & $3 \cdot(1 / 3)$ & $3 \cdot(1 / 6)$ & $3 \cdot(1 / 3)$ & $2 \cdot(1 / 6)$ & $25 / 6$ & + & $4 a$ \\
\hline $\begin{array}{l}\text { (b) number of } \\
\text { (b) process inputs } \\
\text { (a) to manufacturing }\end{array}$ & $3 \cdot(1 / 3)$ & $3 \cdot(1 / 6)$ & $3 \cdot(1 / 3)$ & $2 \cdot(1 / 6)$ & $25 / 6$ & - & $4 b$ \\
\hline $\begin{array}{l}\text { (b) types of } \\
\text { (a) material inputs } \\
\text { (a) to manufacturing }\end{array}$ & $3 \cdot(1 / 3)$ & $3 \cdot(1 / 6)$ & $2 \cdot(1 / 3)$ & $2 \cdot(1 / 6)$ & $21 / 2$ & + & $5 a$ \\
\hline $\begin{array}{l}\text { (a) number of } \\
\text { (a) material inputs } \\
\text { (a) to manufacturing }\end{array}$ & $3 \cdot(1 / 3)$ & $3 \cdot(1 / 6)$ & $2 \cdot(1 / 3)$ & $2 \cdot(1 / 6)$ & $21 / 2$ & - & $5 b$ \\
\hline
\end{tabular}

Notes: The final score is calculated by multiplying each score by a weighting factor and by then adding the weighted scores together. Whether an intervention area focusses on the (a) types of inputs or (b) number of inputs, is only included in the ranking by the addition of a letter " $a$ " or "b" to a rank

Table VIII. The final ranking

which rankings are the least certain and, thus, require additional work the most. The analytic hierarchy process makes explicit how the final ranking is composed. Therefore, it is easy to add to or improve the current reasoning.

\subsection{Conclusion}

This study's goal was to determine where one needs to intervene to be most effective. The answer is that one must prioritize intervention areas as follows: material inputs to the operation phase; process inputs to the operation phase; products' longevity; process inputs to the manufacturing phase; and material inputs to the manufacturing phase. 
SASBE 8,4
These results are generalizations, expressed as rules of thumb, and relying on rules of thumb is always risky. However, most decisions are not made on the basis of rigorous analysis. These rules of thumb can help decision makers prioritize what is most important. When that happens, they will be one step closer to solving the problem of depleting resources.

\section{References}

Alexander, C., Ishikawa, S., Silverstein, M., Jacobson, M., Fiksdahl-King, I. and Angel, S. (1977), A Pattern Language: Towns, Buildings, Construction, Oxford University Press, New York, NY.

Allwood, J.M., Ashby, M.F., Gutowski, T.G. and Worrell, E. (2011), "Material efficiency: a white paper", Resources, Conservation and Recycling, Vol. 55 No. 3, pp. 362-381.

Ashby, M.F. (2012), Materials and the Environment: Eco-Informed Material Choice, 2nd ed., Butterworth-Heinemann, Waltham, MA.

Babbitt, C.W., Kahhat, R., Williams, E. and Babbitt, G.A. (2009), "Evolution of product lifespan and implications for environmental assessment and management: a case study of personal computers in higher education”, Environmental Science \& Technology, Vol. 43 No. 13, pp. 5106-5112.

Blengini, G.A. and Di Carlo, T. (2010), "The changing role of life cycle phases, subsystems and materials in the LCA of low energy buildings", Energy and Buildings, Vol. 42 No. 6, pp. 869-880.

Bocken, N.M.P., de Pauw, I., Bakker, C. and van der Grinten, B. (2016), "Product design and business model strategies for a circular economy", Journal of Industrial and Production Engineering, Vol. 33 No. 5, pp. 308-320.

Boulding, K.E. (1966), "The economics of the coming spaceship Earth", in Jarrett, H. (Ed.), Environmental Quality in a Growing Economy, Johns Hopkins University Press, Baltimore, MD, pp. 3-14.

Brand, S. (1994), How Buildings Learn: What Happens After They're Built, Viking Press, New York, NY.

Czichos, H. (2006), "Materials and their characteristics: overview", in Czichos, H., Saito, T. and Smith, L. (Eds), Springer Handbook of Materials Measurement Methods, Springer Science+Business Media, Würzburg, pp. 95-102.

Danger, M., Daufresne, T., Lucas, F., Pissard, S. and Lacroix, G. (2008), "Does Liebig's law of the minimum scale up from species to communities?", Oikos, Vol. 117 No. 11, pp. 1741-1751.

Diederen, A. (2010), Global Resource Depletion: Managed Austerity and the Elements of Hope, Eburon Academic Publishers, Delft.

Eekhout, M. (1997), POPO, Process Organisatie Voor Product Ontwikkeling, Delft University Press, Delft.

Eguchi, T., Schmidt, R. III, Dainty, A., Austin, S. and Gibb, A. (2011), "The cultivation of adaptability in Japan”, Open House International, Vol. 36 No. 1, pp. 73-85.

Entrop, A.G. and Brouwers, H.J.H. (2010), "Assessing the sustainability of buildings using a framework of triad approaches", Journal of Building Appraisal, Vol. 5 No. 4, pp. 293-310.

European Parliament (2010), "Directive 2010/31/EU on the energy performance of buildings", available at: http://eur-lex.europa.eu/ (accessed February 8, 2018).

Gijsbers, R. (2011), Aanpasbaarheid van de draagstructuur: Veranderbaarheid van de dragger op basis van gebruikerseisen in het kader van Slimbouwen, Universiteitsdrukkerij Technische Universiteit Eindhoven, Eindhoven.

Gorban, A.N., Pokidysheva, L.I., Smirnova, E.V. and Tyukina, T.A. (2011), "Law of the minimum paradoxes", Bulletin of Mathematical Biology, Vol. 73 No. 9, pp. 2013-2044.

Hayek, F.A. (1967), Studies in Philosophy, Politics and Economics, The University of Chicago Press, Chicago, IL.

Hicks, C., Heidrich, O., McGrovern, T. and Donnelly, T. (2004), "A functional model of supply chains and waste”, International Journal of Production Economics, Vol. 89 No. 2, pp. 165-174. 
Krausmann, F., Gingrich, S., Eisenmenger, N., Erb, K., Haberl, H. and Fischer-Kowalski, M. (2009), "Growth in global materials use, GDP and population during the 20th century", Ecological Economics, Vol. 68 No. 10, pp. 2696-2705.

McDonough, W. and Braungart, M. (2002), Cradle to Cradle: Remaking the Way we Make Things, North Point Press, New York, NY.

Meadows, D.H. (1999), Leverage Points: Places to Intervene in a System, The Sustainability Institute, Hartland, VT.

Meadows, D.H., Meadows, D.L., Randers, J. and Behrens, W.W. (1972), The Limits to Growth: A Report for the Club of Rome's Project on the Predicament of Mankind, Universe Books, New York, NY.

Oxford Dictionary of Chemical Engineering (2014), Oxford Dictionary of Chemical Engineering, Oxford University Press, Oxford.

Oxford Dictionary of Economics (2012), Oxford Dictionary of Economics, 4th ed., Oxford University Press, Oxford.

Persson, A. and Ryals, L. (2014), "Making customer relationship decisions: analytics v rules of thumb", Journal of Business Research, Vol. 67 No. 8, pp. 1725-1732.

Rant, Z. (1956), "Exergie, ein neues Wort für 'Technische Arbeitsfähigkeit', Forschung im Ingenieurwesen, Vol. 22 No. 1, pp. 36-37.

Rittel, H.W.J. and Webber, M.M. (1973), "Dilemmas in a general theory of planning”, Policy Sciences, Vol. 4 No. 2, pp. 155-169.

Ross, D.T. (1977), "Structured analysis (SA): a language for communicating ideas", IEEE Transactions on Software Engineering, Vol. SE-3 No. 1, pp. 16-34.

Saaty, T.L. (1990), "How to make a decision: the analytic hierarchy process", European Journal of Operational Research, Vol. 48 No. 1, pp. 9-26.

Shahbazi, S., Wiktorsson, M., Kurdve, M., Jönsson, C. and Bjelkemyr, M. (2016), "Material efficiency in manufacturing: Swedish evidence on potential, barriers and strategies", Journal of Cleaner Production, Vol. 127, pp. 438-450.

Stahel, W.R. (1984), "The product-life factor", in Orr, S.G. (Ed.), An Inquiry into the Nature of Sustainable Societies: The Role of the Private Sector, HARC, Houston, TX, pp. 72-96.

Stahel, W.R. (2010), The Performance Economy, 2nd ed., Palgrave Macmillan, London.

Thomsen, A. and van der Flier, K. (2009), "Replacement or renovation of dwellings: the relevance of a more sustainable approach", Building Research \& Information, Vol. 37 Nos 5/6, pp. 649-659.

Tversky, A. and Kahneman, D. (1974), "Judgment under uncertainty: heuristics and biases", Science, Vol. 185 No. 4157, pp. 1124-1131.

United Nations (1992), "United nations framework convention on climate change", available at: http:// unfccc.int/ (accessed February 8, 2018).

von Bertalanffy, L. (1968), General System Theory: Foundations, Development, Applications, George Braziler, New York, NY.

\section{Corresponding author}

Patrick de Laat can be contacted at: p.delaat@utwente.nl

For instructions on how to order reprints of this article, please visit our website:

www.emeraldgrouppublishing.com/licensing/reprints.htm

Or contact us for further details: permissions@emeraldinsight.com 